on the kidneys; yet it is not an uncommon thing to see prescriptions containing a saturated solution with an excess of the salt; the patient directed to take a teaspoonful of this mixture every one, two or three hours. The question very naturally arises, how many cases of fatal kidney disease might not have occurred had chlorate of potassium not been employed. I have not given a grain of the salt in diphtheria for many years, and since the adoption of antitoxin have given but few drugs. Crsually in conjunction with the injection of antitoxin $I$ would give calomel pretty freely for its cathartic effect, advise the free administration of beef tea, sterilized milk, coffee, and if the patient desired any carefully prepared food, and give a prescription combining a few drops of tr. ferri chlorid. in glycerin and syrup, to be given hourly, more to occupy the mind of the nurse than for any other purpose. If there was great restlessness, small doses of chloral and morphia to procure the desired sleep, as you are aware nearly all cases of diphtheria are attended with considerable restlessness. After exfoliation of membrane and subsidence of fever, I would give small doses of quinia and strychnia; quinia sulph. gr. xv; liq. strychnia acetat. (Hall's) 3i; yerbazin (Lilly) ऊiii. M. Sig.: Half teaspoonful every four hours to child one year old, and order its continuance for not less than three or four weeks. Of the various local applications administered I think most of that of Loeffler, and in young children $I$ have diluted the solution with alcohol and water, and directed that the mouth be swabbed out occasionally with this preparation. In the case of older children and adults. would advise the use of the solution in full strength. The preparation consists of menthol, $2 \frac{1}{3}$ drams dissolved in 9 drams of toluol, 1 dram liq. ferri chlorid., and alcohol, 2 ounces.

Of the seventy cases of diphtheria treated by the writer, abscess did not occur in any, of cutaneous manifestations one, a slight urticaria occurring fourteen days after injecting a girl, aged 8 years, with Behring's antitoxin No. 2. This patient had also some slight manifestation of articular trouble in left hip, but the mother, a very intelligent lady, said the child had previous to her illness from diphtheria frequently complained of joint pains, and she thought her rheumatic. Diphtheritic paralysis was noted in one case, was of short duration; in this child there was irregular heart action occurring at the same time of paralysis, about twelve days after receiving the antitoxin. Albuminuria was noted in five cases; one of these was a case of diphtheria supervening upon measles; a boy five years old had a severe case of measles, and on the eighth day of that disease was attacked with croup, which was proven diphtheritic bacteriologically.

There was abundant evidence that the formation of the false membrane was checked; that its exfoliation was hastened, that the throat was free from membrane earlier than in cases not treated with antitoxin. It was clearly apparent from all the manifestations that the toxemia was relieved and lessened. The health officer's record shows that cases treated with antitoxin were discharged convalescent in average of less than seven days while those treated with other methods had an average of ten days. Of five cases having the appearance of being mild, treated by the writer without antitoxin, two died. Of the three recoveries, one was unable to walk from September 20 to November 11, another was feeble for some weeks in spite of careful nursing and continued administration of tonic remedies. One of these cases was so mild in appearance that the mother protested against the use of antitoxin, said she would not believe the child was sick if she did not see the swollen glands and exudation in throat. This child died ten days after the invasion of the disease from laryngeal stenosis, expired within half hour after symptoms of croup.

Experience and statistics all show the importance of early treatment by serum, mortality increasing with the days of the disease before treatment. Under the influence of early serum treatment the disease loses its progressive charater and this is true in regard to laryngo-stenosis. Of the seventy cases there was but one instance in which laryngo-stenosis symptoms developed. In many cases of very active glandular inflammation with abundant formation of membrane, the effects of the treatment were very striking. Within thirty-six hours in some of the most severe cases there was marked improvement in the general condition, improvement of pulse, fall of temperature and considerable, if not complete, exfoliation of membrane. The limitation of time makes it impossible to discuss the position of antitoxin treatment of diphtheria fully, and I will not consume the time of this Convention with statistics, but will conclude by saying that in my opinion all patients are benefited by the treatment when administered in time to accomplish any results with a reasonable hope of recovery. The administration of antitoxin does away with the necessity for any other but the use of local disinfectants to prevent or limit the growth of bacteria in the throat and supporting treatment.

\section{DISEASES OF THE LACHRYMAL GLANDS.}

Read before the Nebraska State Medical Society at Lincoln, May, 1896. BY H. S. BELL, M.D.

KEARNEY, NEB.

Diseases of the lachrymal passages are frequently brought to the attention of the general practitioner. and $I$ am inciined to believe that our substantial knowledge of the causation, course and treatment of these diseases is not as full and practical as it should be.

The reason for this scant information can not be explained by the relative infrequency of this class of cases, but mostly from the comparatively little attention writers and teachers have heretofore given this subject. Believing this, I have thought I could best serve this society by a discussion of this very common, but too much neglected class of diseases.

The diseases which most frequently affect the lachrymal passages, are those involving the ducts leading from the eye. Near the inner canthus of each eye there may be found two small openings, one in the upper and one in the lower lid, called puncta. These are the orifices of the canaliculi, two very small canals leading into the lachrymal sac, which is the upper dilated end of the nasal duct. In this expanded pouch, or lachrymal sac, is the most common seat of disease, and from this vulnerable point the trouble is liable to involve either the nasal duct or the canaliculi or both.

The nature of the diseases affecting these passages is mucous and purulent inflammation. The most common form is a catarrhal inflammation of the lachrymal sac and its ducts, the most prominent symptom of which is an overflow of tears, and it is for the relief of this symptom the patient first seeks adrice. 
The tears accumulate in the lachrymal sac and distend it in such a manner that it stands out from the side of the nose as a distinct prominence, and for the relief of this fullness the patient is obliged to empty it several times a day by pressing it with the finger in an upward and inward direction. This pressure will often cause the watery secretion to be discharged in a continuous stream as if from a hypodermic needle. If the conditions upon which this catarrhal form of the disease depend are not relieved, it wili finally result in what is termed "blennorrhea" or mucocele, which is characterized by a mucous or gelatinous discharge, which the patient presses out with the finger. Dacryocystitis is an acute purulent inflammation of the lachrymal sac, and the skin and cellular tissue just below the inner canthus of the eye becomes swollen, red and tender to pressure; in fact, the symptoms of a localized cellulitis with abscess. This acute form of the disease is not so common as the catarrhal variety, and requires prompt treatment to prevent a fistulous opening in the lachrymal sac. It is refreshing to find such a unanimity of opinion as to the causation of these lachrymo-nasal affections. It is fully agreed that they have their starting place in subacute or chronic coryza. In fact, chronic rhinitis is said to be not only the cause of all the affections of the lachrymal ducts, but to be the prolific source of most all the inflammations of the ocular and palpebral conjunctiva. Dr. Ziegler, of Philadelphia, in the New York Medical Journal of Nov. 3, 1894, says: "I think we may safely say that fully 90 per cent. of corneal lesions take their origin directly from preëxistent pathologic processes affecting the intranasal tissues and secretions."

Dr. Woodruff, of Auburn, N. Y., in the Medical Record of April 25, 1896, in a résumé of a recent work by Dr. Finck, of Hamburg, Germany, says: "Not a few affections of children can be traced back to a chronic coryza." "Zieme even asserts that two-thirds of all eye diseases are due to nasal affections." "Von Hasner found that among fifty-nine cases of diseases of the lachrymal duct, fifty-one showed a pathologic condition of the nasal cavities." J. Michel and Seifert observed among thirty-eight cases of dacryoblennorrhea, thirty-seven with affections of the nose. Farravelli and Kruch found among cases of diseases of the lachrymal sac, thirty showing nasal catarrh. The consensus of opinion is overwhelming that lachrymal and ophthalmic diseases have their origin in the catarrhal inflammations of the nasal turbinals. From what has been said of the causation of diseases of lachrymal apparatus, it would seem the treatment would be exceedingly simplified, and should be directed to the existing coryza. This is the logical conclusion and the natural key to the successful and intelligent treatment of this class of affections. Expediency, however, will sometimes control in the decision upon a given line of attack. Little children, in whom these diseases mostly abound, are naturally timid and impulsively shrink from the attentions of those with whom they are unfamiliar. They will not even permit their parents to use the simple means of treating these nasal inflammations. After having fully posted myself on the etiology and pathology of these lachrymo-nasal diseases, and lamenting the difficulties with which $I$ was handicapped in conducting their logical treatment, I read a paper by Dr. P. Richard Taylor, Louisville, $\mathrm{Ky}$., in the issue of Jan. 4, 1896, of the Jovrnal, where he advocated the use of a tube which he designed for the treatment of these lachrymal duct diseases. I had previously read in the Medical Record of June 1, 1895, of "A Simple and Effective Method of Keeping the Obstructed Lachrymal Duct Open," and which was said to be a "trick" worth knowing. This method by Dr. Walter N. Vilas, of El Paso, Texas, consisted in passing a small-sized probe armed with a canula through the nasal duct, then the probe is withdrawn and through the canula is passed a silkworm gut suture, the lower end of which is brought out through the nose and a split shot is clamped upon it. The canula is now withdrawn, and the silkworm gut ligature is drawn up until its further progress is arrested by the shot within the nose, when another shot of lead or aluminum is clamped upon the strand of gut as it emerges from the inner canthus of the eye. It was said in the article referred to that this method had been tried in a number of cases of lachrymal obstruction and abscess of the lachrymal sac with unfailing success and commends itself for its. simplicity, practicability and radical effectiveness, as well as the important consideration of abridging the treatment of these cases to one sitting.

Dr. Taylor's "tube is seven-eighths of an inch long and three-eigh ths inch angle, and can be made of any size and of any metal. It has a lateral slit on both sides of the short end, leaving a duckbill snout with upper and lower blades, both of which are to be beneath the surface of the lids or entirely in the passage and hidden from view. The slit prevents the soft tissues from closing the opening of the tube or hindering the passage of the tears through the tube." Each of these methods is designed to effect a cure by drainage. I had about made up my mind to try the plan, but in the meantime the method of Dr. Taylor engaged my attention and appealed to my judgment as being the best. Having three patients with obstruction of the nasal duct with the prominent symptom of weeping eye, I ordered three of Dr. Tay. lor's tubes. Two of my patients were children under $\tilde{5}$ years of age. One of these, a little girl, had had frequent attacks of dacryocystitis, which had resulted in: openings from the lachrymal sac through the skin. just below the inner canthus. From these fistulous tracts pus and tears were constantly escaping, produc-. ing an ugly eczematous eruption over that portion of the cheek. This child was given chloroform, the lower puncta entered by a Weber probe-pointed canaliculus knife, the canal was slit into the lachrymal sac, when, with Bowman's set of probes, the nasalduct was rapidly dilated and this tube, which was introduced in January last, was inserted. I removed it a few days ago for the purpose of exhibiting it to this society to-day. I shall, upon my return home, reintroduce it. The fistulous openings have closed, the eczema disappeared and nothing remains but a faint cicatricial scar. The conjunctivitis with its purulent. exudation has also disappeared.

The second case was a child presenting only the catarrhal form of the lachrymal sac with obstruction to the passage of tears through the nasal duct. This child also had chronic conjunctivitis. Prout, of Brooklyn, has described this condition as conjunctivitis lachrymalis, and adds that it can not be cured except by relieving the obstruction to the nasal duct. This child was anesthetized, the lower canaliculus slit into the lachrymal sac, and with the same probepointed knife the nasal duct invaded and the stricture. cut, after which Bowman's probes were rapidly intro- 
duced and a medium-sized tube inserted. After some weeks I decided that the angle of the tube was too long, as it rubbed the eyeball and increased the conjunctivitis. The child was again given an anesthetic, the tube removed and about one-half the short arm of the tube was cut off, and again introduced. This was two months ago. The eye symptoms rapidly disappeared, as well as the overflow of tears.

My third case was a young man 23 years old with mucocele of the sac of twelve years' standing. In February of this year, with local cocain anesthesia, I did the same operation with the best result.

\section{EMPYEMA OF ANTRUM SIMULATING CARIES OF TEETH; AND A SIMPLE METHOD OF TRANSILLU. MINATION. \\ BY HENRY G. OHLS, M.D. CHICAGO.}

About one year ago I had occasion to examine an antrum, in a case where severe pains in the distribution of the right facial nerve, with tenderness over the malar prominence indicated the probability of empyema. The classical symptom of pus escaping from the hiatus semilunaris and visible on the outer surface and lower edge of the middle turbinated was lacking. A competent dentist had diagnosed an inflammation of the dental nerves of the first and second right upper molars and had made several applications through the root canals to destroy the nerves. Fail ing at last to relieve the pain in that way, the first molar was extracted and after a few days more of treatment and terrific pain, the second molar also was extracted with a large root abscess. Passing a strong curved probe into the antrum through the socket of the tooth, gave vent to about two drachms of thick pus and was soon followed by relief from pain that had been agonizing most of the time for three weeks.

On the evening before the last extraction, I suspected the presence of pus in the antrum on account of the great swelling of the middle and lower tubinated, which might be sufficient to prevent any pus escaping into the middle meatus. I thereupon attempted to transilluminate with Ingals' incandescent lamp, but found that the battery was too far exhausted to give the necessary current. Sufficient current remained, however, to heat the ordinary cautery electrodes and I used a coil of platinum wire, guarding it by a test-tube with a cork cut in two and the halves hollowed out to receive the wires of the electrode. Since then I have used the electrode guarded by a plain two-dram homeopathic vial with entire satisfaction. The vial can be held by the neck between the patient's lips so that the cork prevents any light escaping to confuse the operator. The only mishap I have experienced in a number of trials is the minor one of melting my coil, which can easily be avoided by interrupting the current every few seconds just before the melting point is reached. If the electrode is made of tubing with a coil of platinum wire that slips into the end of the tubes, the coil can be very readily replaced at the expense of a few cents. The current should be slightly greater than that used for cauterization, but can readily be obtained from any cautery battery by cutting out a little more resistance. By covering the vial with opaque paper except at the end and applying the end to the orbital surface of the frontal ridge some illumination of the normal frontal sinus can be obtained in subjects with prominent ridges. I think some assistance in the diagnosis of frontal empyema may be expected from this proceddure, though I have not obtained very satisfactory results. As to the danger of breaking the vial in the mouth, I must confess to feeling some timidity at first, but a large number of trials dispelled this fear. A metal guard would certainly prevent any danger of that kind. Possibly a refiector might be placed beneath the electrode to increase the light, but I have found no case in which the electrode did not furmish ample light. A striking example of the danger in depending on the regular transillumination lamps was read by Jonathan Wright, M.D., before the Laryngologic Section of the Academy of Medicine and reported in the Brooklyn Medical Journal of July, 1895. That case presented the classical history and symptoms of empyema of the antrum. Dr. Wright said: "Unfortunately, my transillumination lamp was out

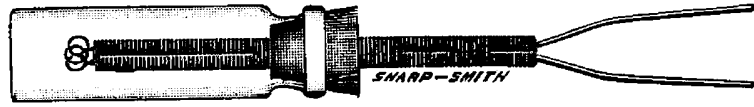

of order, so that I could not apply that test." Upon extracting a diseased tooth and drilling through the floor of antrum no pus was found. "The only conjecture that I could then make was that there was pus in the frontal sinus, but he declined with emphasis the suggestion that he have his frontal sinus opened by external incision. I did not see the patient again, but since then I have not made a diagnosis of antrum trouble without using the transillumination lamp."

Although $I$ have not read of this method being used before I shall be surprised if such a simple procedure has escaped the myriad workers with all the essentials actually in their hands daily. Any suggestion which will give increased usefulness to instruments already in common use for other purposes should be appreciated by physicians, who are so often solicited to buy expensive instruments associated with the names of our inventive confrères, to their advertisement and the financial profit of the instrument maker.

34 Washington Street.

\section{SUBCUTANEOUS INJECTIONS OF SUB. LIMATE AS A CURE FOR CERE. BRO-SPINAL MENINGITIS.}

BY J. D. SMITH, M.D. PaDUCah, KY.

In the Jotrnal of Feb. 15, 1896, page 345, quoting from Sem. Méd., Jan. 15, 1896, I find that, "An Italian, Dr. Dazio, suggested the above-named treatment, and with it, Dr. Consalvi, of Casoli, has recently treated successfully nine cases."

I desire to say that I inaugurated a similar treatment at Dyersburg, Tenn., in the spring of 1885 .

Having seen as consulting physician, a Mr. McC., of Fowlk's Station, four miles from Dyersburg, in the midst of vigorous manhood, die in great agony with cerebro-spinal meningitis, and two days later a youth of 14 years named Martin, in the town of Dyersburg, sicken and in twenty-four hours die as quietly as one going to sleep; and having practiced through two former epidemics of the disease with little or no 